\title{
Improving food provision in a Guyanese home for the elderly: a participatory approach
}

\author{
Gillian Hewitt ${ }^{1, *}$, Alizon Draper ${ }^{1}$, Suraiya Ismail ${ }^{1}$ and Sybil Patterson ${ }^{2}$ \\ ${ }^{1}$ Centre for Public Health Nutrition, School of Integrated Health, University of Westminster, 115 New Cavendish \\ Street, London WIW 6UW, UK: ${ }^{2}$ Guyana Association of Professional Social Workers, Georgetown, Guyana
}

Submitted 17 November 2005: Accepted 4 July 2006: First published online 5 March 2007

\begin{abstract}
Objectives: To conduct a needs assessment of all aspects of food provision in a residential home and to evaluate a subsequent nutrition intervention.

Design: An intervention study using a before and after design. A participatory approach was adopted and quantitative and qualitative methods used throughout. The intervention involved a revised menu, kitchen equipment, and establishing wholesale shopping and food donations.

Setting: A residential home for senior citizens in Guyana.

Results: Meals at the home were nutritionally inadequate and deeply unpopular with the residents. Intakes of fruits and vegetables were low and the home was heavily reliant on donated soya mince and rice. Meals were served within an eight-hour period to accommodate the staff's hours of work. Cutbacks in the food budget indicated that the financial state of the home explained some of the problems. The intervention was unable to address all problems identified, but led to substantial improvements in the nutritional adequacy of the food provided following the inclusion in the menu of a number of nutrient-dense foods such as chicken liver. The new menu was acceptable to the cooks and largely popular with the residents, although some problems persisted.

Conclusions: The results show that improvements in the nutrient profile of the diet could be achieved with a flexible, community-based, participatory approach that addressed all elements of a home's food provision system. The changes also proved largely popular with the residents, thus potentially contributing to their quality of life.
\end{abstract}

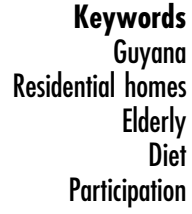

The most striking demographic trend of the 21st century will be the increasing number and proportion of elderly people in all regions of the world. As their numbers increase there is a growing urgency for nations to address the health and social care needs of their elderly, and this is particularly important in countries whose younger adult populations are under threat through HIV/AIDS or are absent through migration. Guyana is a good example of the latter; in 2000 the dependency ratiof was 8 , but it is predicted to rise to 49 by $2050^{1}$.

Residential homes for the elderly have existed in developing countries for decades and are far more prevalent than is often recognised; for example, there are nearly one thousand in India ${ }^{2}$. In Guyana, a mix of state and private residential provision exists, with one large, publicly funded home and over a dozen private homes run by charities and religious organisations.

†Dependency ratio is the ratio of the population aged 65 years or above to the population aged 15-64 years, expressed as number of dependants per 100 persons of working age. The UK projection for 2050 is 38 .
Nutritional status is an established component of physical and mental health at all ages ${ }^{3}$. In addition, undernutrition is related to functional ability, the 'ability to perform basic activities of daily life without support ${ }^{\text {, }}$, such as feeding oneself, dressing and going to the toilet. Functional ability depends on a number of factors including muscular strength, cognitive status and dexterity, and is crucial for an older person's independence and self-sufficiency. From a social perspective food and meals can also be a determinant of quality of life for older people $e^{5}$. An adequate and desirable diet therefore has multiple potential benefits for the elderly, including those in residential care.

The participatory approach to community development has been gaining popularity for over 30 years and is now well entrenched in the mainstream development discourse $^{6}$. In the present study we adopted a participatory approach so that the opinions and perspectives of the residents and all those involved in food provision in a Guyanese residential home would be heard. It was hoped that the consequence of this involvement would be an acceptable intervention that would be practically feasible 
and would engage the residents and staff and hence have a greater chance of success. The aims and benefits of participatory development are much debated ${ }^{6-8}$. The complex participatory process of this study was evaluated in a detailed qualitative evaluation ${ }^{9}$ which will be reported elsewhere.

The objectives of the present study were to conduct a comprehensive needs assessment of all aspects of food provision in a residential home and to evaluate a nutrition intervention designed using the information from the needs assessment. A participatory approach was adopted and a combination of quantitative and qualitative methods used throughout.

\section{Methods}

\section{Subjects and setting}

The study was conducted in a home for senior citizens in an urban area of Guyana, the poorest country in the Englishspeaking Caribbean ${ }^{10}$. The home could accommodate 38 residents and housed men and women, although the latter were in the majority. Ages of the residents ranged from 73 to 98 years with a mean of 85.1 years. The mean body mass index of 19 residents (five men) was $23.3 \mathrm{~kg} \mathrm{~m}^{-2}$, with four below $18.5 \mathrm{~kg} \mathrm{~m}^{-2}$ and five above $24.9 \mathrm{~kg} \mathrm{~m}^{-2}$. Eleven residents were not measured after failing a cognitive screening test or because height or armspan measurements could not be taken?.

The home was a private residential home, i.e. it did not provide nursing care but it did provide three meals a day. It was overseen by a committee of volunteers whilst dayto-day management was undertaken by a paid administrator with four domestic staff. The home was in a poor state of repair and struggling financially. Rent was $\$ 8000$ Guyanese a month at the time of the study, over four times the basic state pension.

The study was part of a doctoral research project that aimed to improve the health, nutrition and quality of life of the residents of two homes. The study was approved by the ethical committee of the University of Westminster and the home's committee gave written consent to participate.

\section{Baseline needs assessment}

The study began in October 2002 and the nutrition intervention commenced in September 2003. The time in between was spent conducting the needs assessment and planning the intervention. The participatory approach adopted meant that the intervention could not be predetermined; rather it was flexible and responsive to the findings of the needs assessment.

The needs assessment was conducted by one of the authors (G.H.) and a local fieldworker, the latter being based in the home full-time and the former visiting almost daily. Both undertook participant observation, the main method of social anthropology that allows the 'observer to study first hand the day-to-day experience and behaviour of subjects ${ }^{11}$. The investigator and fieldworker took the role of 'participant-as-observer"11: they formed relationships with those being studied and participated in life at the home, but made no attempt to conceal the fact that observations were being made. Both kept unstructured field diaries in which they recorded their observations of the residents, staff, food and meal routines and interactions in the home.

Semi-structured interviews and focus group discussions were also undertaken. Individual semi-structured interviews were conducted with the administrator, the committee chairman and the committee member with responsibility for shopping. Three focus group discussions were conducted with residents (14 in total) and one with the four domestic staff. The participants' perspectives and opinions on all aspects of food provision in the home were explored. Residents were also asked what foods and dishes they had enjoyed in the past, but were not served at the home. All interviews were conducted by the author or fieldworker and tape-recorded, then fully transcribed by the author (G.H.).

The nutritional composition of the food provided by the home was assessed at the institutional level using the consumption units method (see analysis below) ${ }^{12,13}$. Seven non-consecutive days of measurement were included. All food served to the residents from the kitchen was weighed as it was prepared and cooked. Ingredients for cooking were weighed raw. Drinking water was not weighed. Following the meal all leftovers were collected and weighed. A record was made of the gender and ages of all people who had participated in the meal. (Staff took their meals from the same food as the residents.) All foods were weighed to the nearest gram on electronic scales with $2 \mathrm{~kg}$ capacity (model 8020, Soehnle-Waagen GmbH \& Co). No attempt was made to collect information on the food residents ate outside the meals provided by the home. Many residents snacked on their own plain biscuits, but it would not have been possible to observe all snacks being consumed, the residents would have found being questioned about them intrusive, and their responses would have depended on their memory. Prepared meals were also donated occasionally by individuals and religious groups, but the frequency was erratic. The method therefore assessed food provided by the home, not total food intake.

\section{Intervention}

The intervention aimed to address three related issues - the content of the meals provided, food purchasing and expenditure on food - through changes to four aspects of food provision: the menu, shopping practices, food donations and kitchen equipment. It was designed in response to data collected during the needs assessment and remained flexible to changing circumstances as the intervention progressed. It aimed to use existing community resources wherever possible, use only locally available foods and keep within the home's existing food budget. This, it was hoped, would encourage local community 
involvement in the home, keep costs to a minimum and enhance the sustainability of the intervention.

A two-week menu plan was drafted with two objectives: to increase the variety of foods used and improve the nutritional profile of the menu, and to include as many of the dishes as possible that the residents enjoyed. The menu was budgeted to the home's existing food expenditure of approximately $\$ 1000$ Guyanese per person per week (about $\{3.50$ ). Once the intervention commenced, the menu plan was adjusted a number of times in response to new donations, staff working rotas and residents' preferences. The menu was planned by the author (G.H.) and fieldworker.

To improve cost-effectiveness of the new menu, the home's usual practice of purchasing its food weekly from a market stall was changed. Shopping was purchased at local wholesalers with the exception of fresh fruits and greens. Records were kept of all purchases.

Local food producers were approached (by letter and follow-up phone calls) and asked to consider making donations to the home. Six companies began making regular donations of rice (one sack monthly), chicken (50 lb monthly), $20 \mathrm{~kg}$ flour and $2 \mathrm{~kg}$ wheat porridge (fortnightly), margarine ( $48 \mathrm{lb}$ quarterly), cornmeal (12 lb monthly) and 60 packets of pasta (monthly). Two companies also made one-off donations.

The home's kitchen equipment was old, worn and insufficient to implement the new menu. Study funds were therefore used to make a one-off purchase of the necessary equipment.

\section{Outcome evaluation}

At the end of the intervention period (March 2004) semistructured interviews were conducted with the committee secretary and the administrator, and four focus group discussions were conducted with the domestic staff and 14 of the residents. These interviews sought the participants' opinions on the interventions. All interviews were taperecorded and fully transcribed.

The nutritional composition of the food provided by the home was assessed again over seven days using the method previously described.

Participant observation and diary-keeping continued throughout and the study team met regularly to discuss the intervention. Records were kept of these discussions.

Qualitative data in the form of interview transcripts, the field diaries and meeting records were used for subjective outcomes, such as the residents' opinions of the menu. The assessment of the nutritional content of the menu was used for the quantitative outcome evaluation.

\section{Analysis}

\section{Quantitative dietary data}

The total amount of each food consumed was calculated and the nutritional composition of these foods was calculated by hand using the food tables of McCance and
Widdowson ${ }^{14}$, the Caribbean food composition tables ${ }^{15}$ and manufacturer's data. Using an elderly man $(>60$ years) as a base (one consumption unit), consumption units of all other individuals were obtained by calculating their nutrient requirements as a proportion of the requirement of the elderly man. Total consumption units for each meal were obtained by summing the consumption units of all individuals consuming that meal. The total nutrient consumption at the meal was then divided by the total consumption units for that meal, and values for the three meals each day were summed to give the nutrient intake per consumption unit per day. This procedure was followed for each nutrient. A weighted average requirement using the Recommended Dietary Allowances for the Caribbean ${ }^{16}$ was calculated to give a combined nutrient requirement for men and women and the nutrient per consumption unit per day as a proportion of the requirement was calculated, to assess adequacy. Nutrients analysed were energy, protein, fibre, calcium, iron, zinc, and vitamins $\mathrm{D}, \mathrm{C}, \mathrm{B}_{12}$, folate and retinol equivalents.

\section{Qualitative data}

All of the transcripts and meeting reports were included in the analysis but the volume of the diaries was too great to be analysed in the time available so they were sampled. A combined strategy of random sampling and selecting all days that had some event relevant to the whole study was used and this resulted in a sample of 185 days, approximately one-third of the total.

Analysis of the qualitative data followed Ritchie and Spencer's 'framework' approach, a method which facilitates 'systematic analysis within the demands and constraints of applied policy research' whilst remaining grounded in the data and flexible ${ }^{17}$. 'Framework' involves five interconnecting stages: familiarisation with the data, identifying a thematic framework, indexing (applying the framework to the data), charting (rearranging the data according to themes) and, finally, mapping and interpretation. Only the first three stages of 'framework' analysis were followed. Following several readings of the interview transcripts, diaries and meeting reports, two initial thematic frameworks or coding frames were developed: one from the transcripts and the other from the diaries and meeting reports. These were then applied to the data and modified as necessary. The data were then sorted electronically according to the coding frame using 'cut and paste' functions of word processing software. This fragments the data and takes each piece of data out of its context, but notes were made of where each piece of data had originated, who had said or written it, to whom and when. Constant reference to the original transcripts, diary entries or meeting reports was also made during the interpretation stage. The coding frames were open to modification throughout the analysis and memos (analytical ideas and questions) were also kept. 


\section{Results}

\section{Needs assessment}

Table 1 shows the mean energy and nutrient content of the food provided by the home over the seven days of measurement and its adequacy according to the theoretical requirements of the residents. Intakes fell short of requirements for energy and all nutrients except protein, which reached 99\% adequacy, and five nutrients fell at or below 50\% adequacy (fibre, zinc, retinol equivalents, and vitamins $\mathrm{C}$ and $\mathrm{D}$ ).

The qualitative data revealed a number of issues regarding food in the home, i.e. quantity, quality, variety and timing of meals. Illustrative extracts from the qualitative data sources are shown in Table 2.

Most comments from the residents and staff were negative, although some residents were accepting of the situation and showed an understanding of the constraints the home faced. The chairman appeared to be unaware of the situation as he stated his belief that the home still followed a Red Cross menu plan which they had long since abandoned.

Opinions on the quantity of food provided were split, with some residents satisfied with the amount they received and others feeling it was inadequate. Those who found the quantity too little often singled out the afternoon meal (dinner) as being most inadequate. Some residents also resented having to purchase their own snack foods. The cooks also expressed frustration at the amount of food they could serve, yet they and the administrator were strong in their dislike of seeing food 'wasted' and so would serve as little as they thought possible.

The residents were unanimous in their criticisms of the quality of the meals, but the fieldworker's observations of the leftovers varied somewhat, with some meals being returned in far greater quantities than others. Hunger, however, could be driving the consumption of unpopular food. Whilst "chunks"* were hated by the majority of the residents, they had little choice but to eat them.

One of the problems with the 'chunks' was the frequency with which they were served, but there were additional problems with dietary variety. Dinner was frequently either biscuits or bread with jam or nutbutter, the drink at lunchtime was nearly always water, rice was served as often as 'chunks', and 'greens' of any kind were largely absent.

Finally, the timing of the meals was a major issue for the residents, particularly given their concerns over the quantity of food provided at dinner time. Dinner was usually served well before $3.30 \mathrm{pm}$ and breakfast between 8.00 and $8.30 \mathrm{am}$; a gap of up to 17 hours. The residents were aware that the timing was determined by the staff's working

\footnotetext{
"'Chunks' refers to soya mince. The home received it free by the sack.
}

Table 1 Nutritional composition and adequacy of the diet provided in the home at baseline

\begin{tabular}{lcc}
\hline Nutrient & $\begin{array}{c}\text { Weighted mean (SD) } \\
\text { amount per CU per day }\end{array}$ & $\begin{array}{c}\text { Mean (SD) } \\
\text { adequacy (\%) }\end{array}$ \\
\hline Energy $(\mathrm{MJ})$ & $5.76(1.06)$ & $71(13.2)$ \\
Protein $(\mathrm{g})$ & $46.4(15.1)$ & $99(32.4)$ \\
Fibre $(\mathrm{g})$ & $7.6(1.0)$ & $25(3.4)$ \\
Calcium $(\mathrm{mg})$ & $637(105)$ & $91(14.9)$ \\
Iron $(\mathrm{mg})$ & $7.7(1.9)$ & $77(19.5)$ \\
Zinc $(\mathrm{mg})$ & $5.3(1.0)$ & $43(7.6)$ \\
Retinol equivalents $(\mu \mathrm{g})^{*}$ & $289(90)$ & $50(15.8)$ \\
Vitamin D $(\mu \mathrm{g})$ & $0.75(0.4)$ & $30(17.2)$ \\
Vitamin $\mathrm{B}_{12}(\mu \mathrm{g})$ & $1.3(0.7)$ & $85(48.9)$ \\
Folate $(\mu \mathrm{g})$ & $182(57)$ & $91(28.8)$ \\
Vitamin C $(\mathrm{mg})$ & $28(15)$ & $47(25.3)$ \\
\hline
\end{tabular}

$\mathrm{SD}$ - standard deviation; $\mathrm{CU}$ - consumption unit.

* The home used a vitamin-A-fortified oil of unknown strength so intakes will be greater than appear.

hours ( 7.30 am to $4.00 \mathrm{pm}$ ), but were divided on how accepting of this situation they were. As one resident pointed out, not all could 'afford to buy a little biscuits'.

To summarise, the needs assessment showed that the meals at the home were nutritionally inadequate in composition and deeply unpopular with the residents. In particular, intakes of fruits and vegetables were very low and the home was heavily reliant on soya mince and rice, both of which they received free. In addition, the meals were all served within an eight-hour period to fit in with the staff's hours of work. The staff were frustrated at having to produce meals they knew were disliked and to see them returned uneaten. Cutbacks in the food budget, however, indicated that the financial state of the home was the reason for some of the problems.

The findings of the needs assessment were used to formulate the intervention, as described in the Methods section.

\section{Nutritional outcomes}

Table 3 presents the mean energy and nutrient content and the nutritional adequacy of the food provided by the home after the nutrition intervention had been in place for approximately 6 months. Improvements were seen in the percentage adequacy of energy and eight of the 10 nutrients analysed. The exceptions were calcium and zinc which almost halved and remained unchanged, respectively. The adequacy of energy, fibre and vitamin D remained below 90\% despite their increases. The increases in iron, retinol equivalents and vitamins $\mathrm{C}, \mathrm{D}, \mathrm{B}_{12}$ and folate were particularly notable.

The cost of the menu after 29 weeks equated to $\$ 27000$ Guyanese per week.

\section{Qualitative outcomes}

The residents and staff made generally positive comments on the new menu during its implementation and in the final evaluation. Criticisms made during implementation were that the quantity of food at the afternoon meal was still 
Table 2 Extracts from qualitative data collected during the needs assessment

\begin{tabular}{|c|c|c|}
\hline Issue & Extract* & Source \\
\hline \multirow[t]{2}{*}{ General comments } & $\begin{array}{l}\text { What do you think about the food that is prepared here [at the home]? } \\
\text { // [Subdued laughter] // 19: 'That's a problem.' // 44: 'That's a million } \\
\text { dollar question.' // 14: 'A real problem.' }\end{array}$ & FGD transcript (residents) \\
\hline & 'But the food ain't got no standard at all.' (Cook) & FGD transcript (domestic staff) \\
\hline \multirow[t]{3}{*}{ Quantity of food } & $\begin{array}{l}\text { 'You get a bellyful I would say, because I don't eat much, you know. } \\
\text { I does eat, yes, but not that much. You get a bellyful.' (Resident 20) }\end{array}$ & FGD transcript (residents) \\
\hline & $\begin{array}{l}\text { 'It's a good thing I got two cents, I can buy a box of biscuit but before } \\
\text { that I used to hungry, you understand me?' (Resident 27) }\end{array}$ & FGD transcript (residents) \\
\hline & $\begin{array}{l}\text { 'And a small bottle of jam gotta last for the whole week.' Cause if you } \\
\text { done, you gotta answer question... "What make it finish?".' (Cook) }\end{array}$ & FGD transcript (domestic staff) \\
\hline \multirow[t]{2}{*}{ Quality of food } & $\begin{array}{l}\text { 'Because when it come and it ain't got no taste, the way it comes, me } \\
\text { no want no more, you understand... Because, put a little aji, no? } \\
\text { Put a half cube, you understand what I mean? ... And give the food } \\
\text { a palatable taste, not horrible taste.' (Resident 20) }\end{array}$ & FGD transcript (residents) \\
\hline & $\begin{array}{l}\text { 39: 'I don't like.' [chunks] // 13: 'I don't like it at all.' // 39: 'Chunks. } \\
\text { I don't like it.' // 13: 'I don't like it. Cut that out.' }\end{array}$ & FGD transcript (residents) \\
\hline \multirow[t]{2}{*}{ Variety } & $\begin{array}{l}\text { Dinner prepared was bread and nutbutter/jam and this is like a poem } \\
\text { I have to repeat. }\end{array}$ & Fieldworker's diary \\
\hline & $\begin{array}{l}\text { Do you feel you have too much rice? // [Laughter] // 44: 'Strike the nail } \\
\text { upon the head, hit it on the head.' }\end{array}$ & FGD transcript (residents) \\
\hline Timing of meals & $\begin{array}{l}\text { 'The last meal that is served, before four, between three and four. Well } \\
\text { then what happens between the hours of four and eight thirty the } \\
\text { following morning? You must be hungry, see?' (Resident 44) }\end{array}$ & FGD transcript (residents) \\
\hline
\end{tabular}

FGD - focus group discussion.

* Numbers refer to resident identification numbers.

lacking at times and there were too many days without meat.* During the final round of interviews some residents highlighted the continued need for improvement as the quality and quantity of food remained variable, but they recognised that not everyone could be satisfied all the time. The quantity of food served at the afternoon meal remained a problem, to an extent because the time of the meal could not be altered. The following extracts from the final round of focus group discussions with the residents and the author's field diary reflect some of their opinions.

[Resident 17] said the food is $100 \%$ better and he has no problems, all that he is thinking about is what will happen when we're gone. (G.H.'s diary)

'There has been an improvement in the meals - now there is variety; I think everyone will second me. Variety.' (Resident 44)

'There has been some amount of improvement, right, especially in the diet, so doesn't matter, well everybody doesn't like everything but everybody can't like everything.' (Resident 04)

'The meals are improved [but] I would like a little more greens.' (Resident 05)

\section{Discussion}

The needs assessment revealed stark problems with the whole food provision system in the home and these

*On these days a pulse or eggs were used instead. It was not possible to serve meat or fish daily and stay within budget. culminated in meals inadequate in their nutritional composition that were unpopular with the residents. The micronutrient and fibre content of the diet was particularly concerning (Table 1 ). Low fibre, vitamin $\mathrm{C}$ and retinol equivalent content reflected low use of fruits and vegetables: during the seven days of measurement fruit was served four times and vegetables (other than root vegetables) were served three times. Energy intake also fell below the requirement, but the interpretation of this rests on the assumption that the requirement is accurate and this has been challenged ${ }^{18}$. Certainly the physical activity levels of some residents were extremely low, reducing their energy requirement. There were no notable changes in nutritional status across the needs assessment period ${ }^{9}$, suggesting a sufficient energy intake, but some residents' snacking habits may have supplemented deficits in their energy intake from meals. Extensive observations at the home combined with the interviews revealed the depth of the residents' and staff's dislike of the meals, the uneconomical purchasing system and the financial pressure on the food budget.

The introduction of the new menu, supported by the other aspects of the intervention, was largely successful and beneficial to the residents' nutrient intakes and their enjoyment of the meals, although they raised scope for further improvements.

The use of a number of particularly nutrient-dense foods had a noticeable effect on the nutritional composition of the diet. The first of these was chicken liver, which had a profound effect on intakes of iron, vitamin $\mathrm{A}$, folate and vitamin $\mathrm{B}_{12}$. The liver, served on one of the seven measurement days, became the best source of vitamins $\mathrm{A}$ and $\mathrm{B}_{12}$ in the diet (supplying $80 \%$ and $79 \%$ of 
Table 3 Nutritional composition and adequacy of the diet provided in the home following the dietary intervention

\begin{tabular}{lcc}
\hline Nutrient & $\begin{array}{c}\text { Weighted mean (SD) } \\
\text { amount per CU per day }\end{array}$ & $\begin{array}{c}\text { Mean (SD) } \\
\text { adequacy }(\%)\end{array}$ \\
\hline Energy $(\mathrm{MJ})$ & $6.69(1.08)$ & $82(13.1) \uparrow$ \\
Protein $(\mathrm{g})$ & $48.7(8.2)$ & $104(17.5) \uparrow$ \\
Fibre $(\mathrm{g})$ & $9.4(1.6)$ & $32(5.3) \uparrow$ \\
Calcium $(\mathrm{mg})$ & $360(89)$ & $53(11.4)$ \\
Iron $(\mathrm{mg})$ & $11.5(3.9)$ & $115(38.7) \uparrow$ \\
Zinc $(\mathrm{mg})$ & $5.5(1.7)$ & $43(13.1)$ \\
Retinol equivalents $(\mu \mathrm{g})^{\star}$ & $1662(3423)$ & $286(588) \uparrow$ \\
Vitamin D $(\mu \mathrm{g})$ & $1.98(0.7)$ & $79(28.9) \uparrow$ \\
Vitamin $\mathrm{B}_{12}(\mu \mathrm{g})$ & $8.25(18.4)$ & $550(1229) \uparrow$ \\
Folate $(\mu \mathrm{g})$ & $391(238)$ & $195(119.1) \uparrow$ \\
Vitamin $\mathrm{C}(\mathrm{mg})$ & $60(36)$ & $99(60.1) \uparrow$ \\
\hline
\end{tabular}

SD - standard deviation; CU - consumption unit; $\uparrow$ indicates an increase over baseline.

${ }^{*}$ The home used a vitamin-A-fortified oil of unknown strength so intakes will be greater than appear.

the vitamin, respectively) and the second best source of folate and iron (19\% and 10\%, respectively). The use of fruits at breakfast or fruit juice at lunch was of note in improving vitamin $\mathrm{C}$ intakes and tinned fish (both mackerel and tuna were used) was a good source of calcium, vitamin $\mathrm{D}$ and vitamin $\mathrm{B}_{12}$. Blackeye peas and yellow split peas made notable contributions to fibre and folate intakes and increased use of eggs contributed to intakes of iron and vitamins $\mathrm{A}, \mathrm{B}_{12}$ and $\mathrm{D}$.

The percentage adequacy of calcium fell substantially from $91 \%$ to $53 \%$ (Table 3). This was due to the days of measurement coinciding with the home running out of free dried skimmed milk. In its place they used a donation of fresh milk or bought dried or evaporated milk when they had no other option. The fresh, tinned and dried milks were being stretched so the amount of milk used to make the twice daily hot drinks was substantially reduced. The consequence of this was a reduction in energy, protein, calcium and vitamin $\mathrm{B}_{12}$ contents.

Addressing the whole food provision system through the switch to wholesale shopping and the increased quantity of donated food meant that the cost of the intervention fell within the home's previous food budget, and allowed more fruits, greens and pulses to be purchased. The only financial input was the initial cost of the kitchen equipment. The menu cost, however, was calculated over the whole intervention period and the switch to wholesale shopping required substantial amounts of money to be spent in the initial weeks as stocks were established.

The choice of an institutional-level dietary analysis using consumption units means that nothing can be concluded about the diets of individual residents. While the percentage adequacy figures were improved for many of the nutrients, it must be borne in mind that the consumption unit method assumes that food is divided on the basis of requirement and this was not the case. Rather it was divided on the basis of appetite and there will therefore be residents with small food intakes whose nutrient intakes were lower than the results suggest. Although this is a limitation, the method does allow for change in the nutritional composition of the food provided to be assessed and it can be concluded that a resident maintaining the calories they ate will have experienced an increase in nutrient intakes. Their total intake, however, may remain inadequate.

It must be emphasised that this methodology included only the food that the home provided and so is not a measure of total food intake. Some residents had their own snacks, but it is not unreasonable to argue that food provided by the home should attain the level of the nutrient requirement as for some residents it was the only source of food.

The potential for transfer of the intervention to other homes in the Caribbean is reasonable. Planning a new menu using only locally available foods and traditional dishes was quite straightforward, but ensuring the menu fitted in with budgets, shopping practices and staff requirements was a more complicated task. Some professional support might therefore be needed to ensure the menu is appropriate in practical terms and to assure the nutritional composition and balance of the meals.

The home was a complex institutional context ${ }^{9}$ and this has influenced the intervention's continued implementation. Its sustainability depends not only on the food budget remaining sufficient and food donations continuing, but also on the committee and the administrator maintaining commitment to the menu and having the time and skill to implement and oversee it. Changes in the committee have seen commitment remain strong, but it is likely that the presence of the project staff had a substantial impact on the practical aspects of the menu's implementation. More effort to involve the committee and administrator throughout the process may have mitigated this.

The findings of the study show that substantial improvements in the nutrient profile of the diet could be achieved with a flexible, community-based, participatory approach that addressed all the elements of a home's food provision system, from menu-planning to shopping and food preparation. The changes also proved largely popular with the residents, thus potentially contributing to their quality of life. Despite modest achievements in some aspects of food provision, however, substantial scope for improvement remained.

\section{Acknowledgements}

We extend our thanks to the Caribbean Health Research Council for providing a grant to fund the study and to the fieldworker, Ms Eartha Grant.

\section{References}

1 Population Division of the Department of Economic and Social Affairs of the United Nations Secretariat. World 
Population Prospects: The 2004 Revision. New York: United Nations, 2005.

2 HelpAge India. Available at http://www.helpageindia.org/ homesaged.php. Accessed September 2005.

3 World Health Organization (WHO). Nutrition for Health and Development: A Global Agenda for Combating Malnutrition. Geneva: WHO, 2000.

4 Manandhar M. Functional ability and nutritional status of free-living elderly people. Proceedings of the Nutrition Society 1995; 54: 677-91.

5 Vailas LI, Nitzke SA, Becker M, Gast J. Risk indicators for malnutrition are associated inversely with quality of life for participants in meal programs for older adults. Journal of the American Dietetic Association 1998; 98: 548-53.

6 Morgan LM. Community participation in health: perpetual allure, persistent challenge. Health Policy and Planning 2001; 16: 221-30

7 Cooke B, Kothari U, eds. Participation: The New Tyranny? London: Zed Books Ltd, 2001.

8 Kapoor I. The devil's in the theory: a critical assessment of Robert Chambers' work on participatory development. Third World Quarterly 2002; 23: 101-17.

9 Hewitt G. Improving the health, nutrition and quality of life of elderly Guyanese living in residential homes. $\mathrm{PhD}$ thesis, University of Westminster, London, 2005.
10 United Nations Children's Fund (UNICEF). The State of the World's Children 2005. New York: UNICEF, 2004.

11 Waddington D. Participant observation. In: Cassell C, Symon G, eds. Qualitative Methods in Organizational Research. London: Sage Publications, 1994; 107-22.

12 Flores M, Nelson M. Methods for data collection at household level or institutional level. In: Cameron ME, van Staveren WA, eds. Manual on Methodology for Food Consumption Studies. Oxford: Oxford Medical Publications, 1988; 33-52.

13 Gibson RS. Principles of Nutritional Assessment. Oxford: Oxford University Press, 1990; 29.

14 Holland B, Welch AA, Unwin ID, Buss DH, Paul AA, Southgate DAT. McCance \& Widdowson's The Composition of Foods, 5th ed. London: Royal Society of Chemistry, 1991.

15 Caribbean Food and Nutrition Institute (CFNI). Food Composition Tables for use in the English-speaking Caribbean. Jamaica: CFNI, 1998.

16 Caribbean Food and Nutrition Institute (CFNI). Recommended Dietary Allowances for the Caribbean. Jamaica: CFNI, 1994.

17 Ritchie J, Spencer L. Qualitative data analysis for applied policy research. In: Bryman A, Burgess RG, eds. Analyzing Qualitative Data. London: Routledge, 1994; 173-94.

18 Roberts SB, Dallal GE. Effects of age on energy balance. American Journal of Clinical Nutrition 1998; 68: 975S-9S. 